\title{
Passengers Perception on Trans Jogja Service Performance by using Structural Equation $\cong$ Modeling
}

\author{
Nur Seta Mulyasari, Sigit Priyanto
}

\begin{abstract}
Yogyakarta has been one of the busiest cities in Java. Every day, there are people coming and going in this city. Not only those within the city region, but also the ones from its surrounding regencies such as Purworejo, Kulon Progo, Magelang, and Klaten. Therefore, it is necessary to develop public transportation which can provide solutions to this rapid trip movement. Yogyakarta provides Trans Jogja to manage the trip inside the city. Despite using Trans Jogja for daily transportation, passengers may have its perception on how they choose to use this public transportation services. The purpose of this study is to determine the influencing factors of the usage of Trans Jogja based on the perception of its passengers as well as its potential passengers. The method used in this study is divided into quantitative data collection methods and quantitative data analysis. The method of data collection is by distributing questioners to the respondent groups which consist of Trans Jogja passengers and potential passengers. The method of data analysis chosen is the Structural Equation Modelling (SEM) method with Linear Structural Relationships (LISREL) software to analyse the relationship of value, quality, best score, and customer satisfaction to determine the best model for perception analyse of each group. The indicators to measure passenger perceptions and potential passengers are (1) security, (2) safety, (3) comfort, (4) equality, (5) affordability, (6) regularity. The results of passengers' perception on Trans Jogja service performance may become the parameter in improving the quality of the services of the public transportation in Yogyakarta.
\end{abstract}

Keywords: perception factors, passengers, public transportation, satisfaction, comfort, Trans Jogja

\section{INTRODUCTION}

As long as there is a need to move from origin to destination, human will always in need of transportation services. In human activities, transportation services play a very important role in economic growth, development, and society at large. Therefore the demand for transportation services continues to increase according to the times. Efforts to ensure safe and comfortable transportation services require the availability of transportation system, transportation

Revised Manuscript Received on December 05, 2020.

* Correspondence Author

Nur Seta Mulyasar, Department of Civil and Environmental Engineering, Faculty of Engineering, Universitas Gadjah Mada, Yogyakarta, Indonesia. Email: nurseta2018@mail.ugm.ac.id

Sigit Priyanto*, Department of Civil and Environmental Engineering, Faculty of Engineering, Universitas Gadjah Mada, Yogayakarta, Indonesia. Email: spriyanto2007@ugm.ac.id

(c) The Authors. Published by Blue Eyes Intelligence Engineering and Sciences Publication (BEIESP). This is an open access article under the CC BY-NC-ND license (http://creativecommons.org/licenses/by-nc-nd/4.0/) facilities, and transportation infrastructure which reach all regions. Thus, aspects that support the creation of effective and efficient urban transportation services are influenced by several elements such as transportation system (ticketing, information media), transportation infrastructure (roads), terminals/stops/park and ride, transportation facilities (vehicles), and cargo (passenger).

Population growth and increasing levels of affluence reinforce the need for public transport options. A developed society is characterized by a high level of mobility due to the availability of sufficient transportation services at a reasonable price which are managed efficiently and effectively in a good system [1]. Several factors that need to be considered in analyzing the character of travel patterns consist of the number of city residents, land use, city structure, household structure, level of public transport services and individual attributes [2].

The Institute for Transportation and Development Policy states that Bus Rapid Transit (BRT) is a bus-based transportation system with high capacity and speed, and has good quality service at low cost [3]. BRT also combines several elements such as special bus lanes which are generally at road medians, off-board withdrawals, boarding levels, bus priority at intersections, and other elements of service quality (such as information technology and strong branding). The system applied by Yogyakarta BRT, named Trans Jogja, is buy the service system, which is a system of purchasing services from the government to the private sector (operators) to operate public transportation with a certain standard, especially to prioritize services to the user community.

\section{LITERATURE REVIEW}

\section{A. Buy the Service}

The system applied by the Provincial Government of Yogyakarta is a system of purchasing services from the government to the private sector (operators) to operate public transportation with a certain standard, especially to prioritize services to the user community. According to Lefrant, buy the service based transportation management is as follows [4]:

a. Not using a deposit system.

b. Operators only concentrate on service.

c. The driver, bus owner, and other staff will be paid according to the service kilometer.

d. There are service standards that must be met, for example: buses only stop at predetermined stops and times.

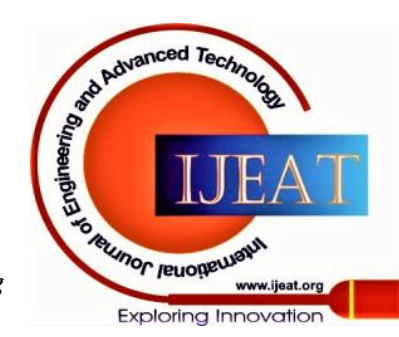




\section{Passengers Perception on Trans Jogja Service Performance by using Structural Equation Modeling}

e. Bus transportation services with buy the service system prioritize public service.

f. Supporting the new system requires special stopping places and an automatic ticketing system to avoid leaks and facilitate evaluation.

\section{B. Public Transportation Service Standard}

According to Goetsch and Stanley, quality is a dynamic condition related to products, services, people, processes, and the environment that meet or exceed expectations [5]. Quality public services are not only determined by those who serve them but also those who want to be satisfied. The principles of quality service are as follows:

a. Processes and procedures must be established in advance;

b. The processes and procedures must be known by all parties involved;

c. Discipline for implementation to adhere to processes and procedures;

d. It needs a review of the processes and procedures by the leadership and can be changed from time to time if necessary;

e. Need to create a climate that is conducive to organizational culture developers to create service quality;

f. Quality means meeting consumer wants, needs, tastes;

g. Everyone in the organization is a partner with other people. Priyanto and Muthohar state that public transportation services can be seen from several aspects as follows [6]:

a. The security aspect in which service users are free from interference such as illegal acts or fear.

b. The safety aspect in which service users are able to avoid the risk of accidents due to humans, infrastructure, and vehicles.

c. The convenience aspect in which service users can enjoy clean, comfortable, composed, and fine conditions.

d. The aspect of equality in which users can be given special services in the form of priority services, accessibility, and facilities, especially for children, elderly people, persons with disabilities and pregnant women.

e. The affordability aspect in regards of affordable rates and easy access to public transportation.

f. The aspect of regularity such as certainty of bus arrivals and departures, bus transport capacities, information facilities, and travel route maps, the frequency of services applied to transportation service users.

\section{Service Equation Model (SEM)}

Structural Equation Modelling (SEM) is a statistical tool used to solve multilevel models simultaneously which cannot be done with linear regression models. SEM is a combination of regression analysis and factor analysis. The equation in SEM describes all the relationships between constructs (dependent and independent variables) involved in an analysis. A construct is a factor that cannot be directly measured or a latent factor represented by several variables. Kline states that many studies use SEM analysis by considering the following [7]:

a. Research generally uses measurement to describe latent variables;

b. Social researchers are very interested in predictions. Making predictions does not only involve a two-variable model, but can involve a more "complicated" model in the form of a structural relationship between several research variables;

c. SEM can serve as well as a measurement and prediction quality analysis, especially in latent variable models.

\section{RESULT AND DISCUSSION}

\section{A. Passenger Characteristics as Respondents}

Passengers from outside the city of Yogyakarta make transfers at the Gamping node and Jombor terminal. This is indicated by the presence of passengers from Kulon Progo, Klaten, Purworejo, and Magelang who use Trans Jogja. This can be a first step in designing a proper park and ride that intersects with the inter-city bus within province or Inter-Provincial bus stops at the outer points of Yogyakarta City. Data on the potential number of passengers who transfer vehicles from public vehicles to private vehicles or online service at the Jombor and Gamping nodes strengthens the reason for the need for node development at the outer points of Yogyakarta City. This potential passenger behavior is due to the fact that Gamping and Jombor Terminal have overnight parking facilities with a large enough capacity. Trans Jogja users are of productive age who are aware of the importance of using public transportation in reducing the level of congestion in the city of Yogyakarta. Meanwhile, another passenger group is over 36 years of age who feel that the Trans Jogja transportation has experienced many good developments since its inception, so they are more comfortable using this transportation. In addition, at this age level respondents are respondents with a high level of education. They feel that the Trans Jogja transportation service is quite reliable and understand the importance of using public transportation for the common interest. The ratio of the number of Trans Jogja passengers between men and women can be said to be balanced. However, female passengers mostly use Trans Jogja services because they feel more comfortable with Trans Jogja services. Based on observations in the field, currently the ethics of Trans Jogja bus transportation are also better, for example, most of the Trans Jogja bus seats are used for older people or priority seats according to their function. Trans Jogja passengers who are loyal to use the service for around 1-5 years. This group feels that the Trans Jogja services are growing rapidly to provide better services. However, Trans Jogja still needs improvement and innovation in order to maximize its services so that Trans Jogja passengers experience a significant increase or have a large enough load factor.Trans Jogja passengers are people with work and study activities because the Trans Jogja route is designed to pass through study and work locations. In addition, the departure and arrival schedules of the fleets and Trans Jogja routes are in accordance with passenger schedules. This shows that Trans Jogja transportation must be able to design the right route based on the destination for work and / or study so that people use Trans Jogja services.$$
\text { Copyright. All rights reserved. }
$$

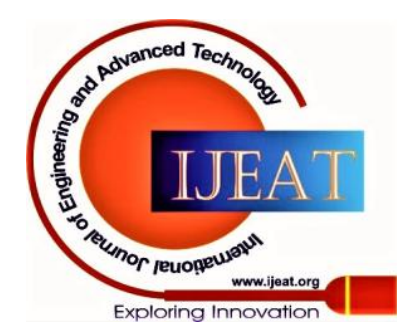


The potential for passengers is dominated by educated groups, seen from the percentage of education they take, so there needs to be an intensive approach in socializing Trans Jogja transportation so that this group moves from private vehicles to Trans Jogja transportation.

Trans Jogja services are used by many students indicating the need for planning according to student needs. Based on the largest education, data on passengers and potential passengers of Trans Jogja shows that Transjogja users are dominated by passengers with undergraduate education, high school, and junior high school. The potential of passengers who are dominated by educated groups requires an intensive approach in socializing Trans Jogja transportation so that this group is willing to switch from private transportation to public transportation.

\section{B. LISREL Analysis}

Analysis is carried out by using LISREL are based on the stages of SEM analysis [8]:

a. Model specifications

Model specifications related to service perceptions

based on passenger respondents and potential passengers can be seen in Figure 1.

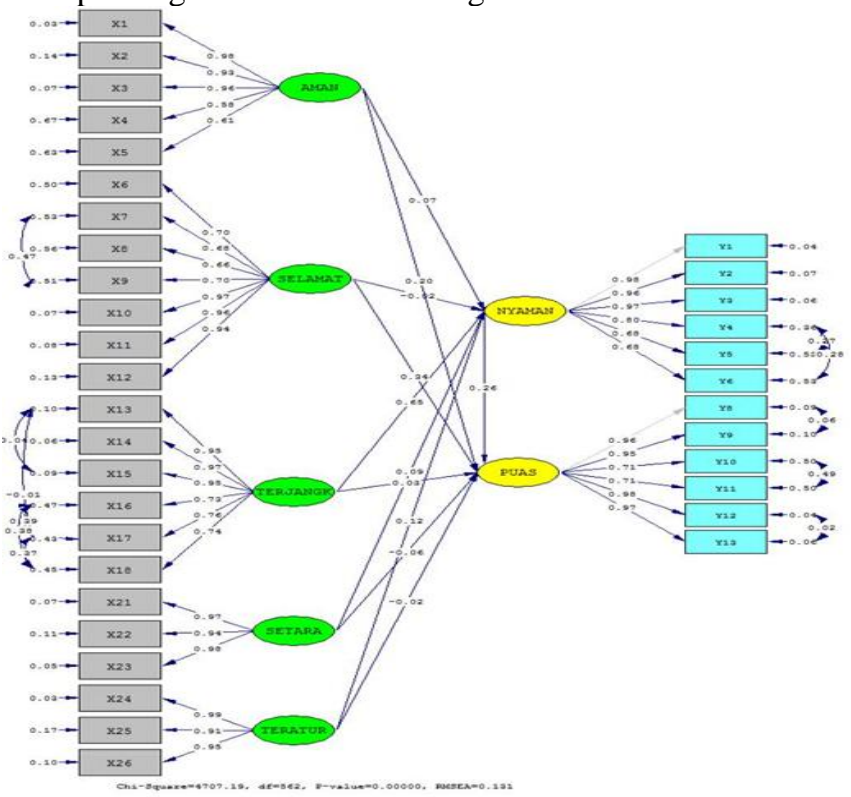

Fig. 1 Loading factor standardized passengers and potential passengers of Trans Jogja

Figure 1 is derived from LISREL. It shows Trans Jogja services flow chart by using five aspects that affect public transport services i.e. security, safety, affordability, equality, and regularity. The chart is moderated to the aspect of comfort and satisfaction of passengers to the services provided by Trans Jogja.

b. Model identification

The model requirement required in SEM is an over identified model, that is, a model in which the number of parameters estimated is smaller than the known number or the value of df $>0$ (over-identified).

\section{c. Model estimation}

The model estimate used in this model is the maximum likelihood processed with LISREL assistance, all loading factor values are valid with an overall value of $\geq 0.5$ so it can be said that all indicators can be used in the process of forming structural equations. The biggest loading factor $\mathrm{X}$ value is the regularity value, which is the information on the arrival of Trans Jogja which is conveyed at the bus stop to the passengers regarding the estimated waiting time for the bus of 0.99 and the smallest loading factor value is the safety factor on the indicator that the closed stop design is safer for passengers. The indicator is 0.58 . This shows that there is information conveyed by the officer regarding the arrival of the Trans Jogja bus to the public while waiting at the bus stop so that Trans Jogja bus users have a certain time. This is an added value in the Trans Jogja service so that users can adjust their travel time. In the absence of security for an uncovered bus stop, potential passengers do not use Trans Jogja transportation because they feel that the bus stop is not suitable for use. Some bus stops are not friendly to passengers because they do not have a roof so that they do not protect passengers from the sun or rain. Some shelters are also not pedestrian friendly because there is no pedestrian access, which reduces the level of security. The biggest loading value of the $\mathrm{Y}$ factor is the value of satisfaction.

Y12 (0.98) is an indicator of an evaluation of public transport by the Government of Yogyakarta towards Trans Jogja operations. It is based on security, safety, affordability, comfort, equality and order. Respondents considered that the Trans Jogja evaluation was very important for the sake of improving public transport services. With an evaluation with appropriate follow-up, it will increase the loading factor of Trans Jogja so that it reduces the number of accidents and breaks down congestion.

\section{d. Model fit test}

1) Evaluation of the overall model

The results of the analysis of goodness of fit (GoF) with the CFA model have a p value of $0.00(<0.05)$ or less good, GFI of 0.72 or marginal fit, AGFI of 0.75 or marginal fit, but other compatibility indexes have shown a value. The good ones are CFI (0.94), NFI (0.93), NNFI (0.93), IFI (0.94) and RFI (0.93) which all have a good fit. Thus it can be said that the proposed model is fit with the data.

2) Evaluate the suitability of the measurement model

The high reliability value is indicated by the $C R$ value $\geq 0.70$ and the diversity of indicator data in the latent variable is acceptable because the AVE value is $\geq 0.7$ so it can be said that all indicators are reliable in building structural equations.

3) Evaluation of the structural model

The measurement equation test results from each indicator to the latent variable using maximum likelihood obtained 34 iteration results with measurement equations which are a model description of each dimension with indicators indicated by the presence of an SLF value above 0.50 in the first order relationship, namely the dimensions and indicators shown in the completely standardized solution and the $t$ statistical value is above 1.96 (significant value). The structural equation model describes a stage of evaluating the causal relationship between latent variables and their dimensions that have an SLF of more than 0.50 at the gamma output and a statistical t value above 1.96 (significant value).

Published By:

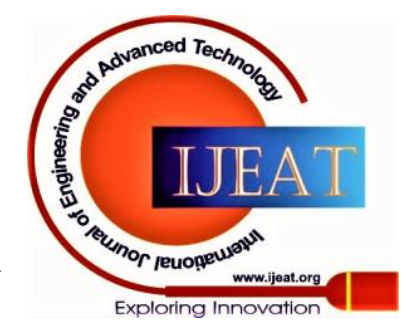

Blue Eyes Intelligence Engineering and Sciences Publication (c) Copvriaht: All riahts reserved. 


\section{Passengers Perception on Trans Jogja Service Performance by using Structural Equation Modeling}

Table-I: Result of SEM analysis on passenger data and potential passengers

\begin{tabular}{|l|l|l|l|l|}
\hline \multirow{3}{*}{ Aspect } & \multicolumn{3}{|c|}{$\begin{array}{c}\text { Passengers and Potential Passengers } \\
\text { Data }\end{array}$} \\
\cline { 2 - 5 } & \multicolumn{4}{|c|}{ Model } \\
\cline { 2 - 5 } & \multicolumn{3}{|c|}{ I } & \multicolumn{2}{c|}{ II } \\
\cline { 2 - 5 } & $\begin{array}{c}\text { path } \\
\text { coefficient }\end{array}$ & t count & $\begin{array}{c}\text { path } \\
\text { coefficient }\end{array}$ & t count \\
\hline Comfort & & & 0.26 & 3.79 \\
\hline Security & 0.073 & 1.50 & 0.20 & 3.21 \\
\hline Safety & -0.23 & -0.47 & 0.34 & 5.22 \\
\hline $\begin{array}{l}\text { Affordabili } \\
\text { ty }\end{array}$ & 0.65 & 13.23 & 0.03 & 0.41 \\
\hline Equality & 0.39 & 2.15 & -0.06 & -1.80 \\
\hline Regularity & 0.12 & 2.65 & -0.02 & -0.41 \\
\hline
\end{tabular}

Based on the results obtained from the analysis of passenger data and potential passengers, the structural equation model is obtained as follows:

Model 1

Comfort $=(0.073 \mathrm{x}$ security $)-(0.23 \mathrm{x}$ safety $)+(0.65 \mathrm{x}$ affordability $)+(0.39 x$ equality $)+(0.12 x$ regularity)

Model 2

$$
\begin{aligned}
\text { Satisfaction }= & (0.26 \mathrm{x} \text { comfort })+(0.20 \mathrm{x} \text { security })+(0.34 \mathrm{x} \\
& \text { safety })+(0.03 \mathrm{x} \text { affordability })-(0.058 \mathrm{x} \\
& \text { equality })-(0.024 \mathrm{x} \text { regularity })
\end{aligned}
$$

The coefficient of determination in equation model 1 and equation model 2 is as follows.

(a) The quality of comfort aspect, security aspect, safety aspect, and affordability aspect are able to explain the satisfaction aspect variable by $74 \%$ and the remaining $26 \%$ is explained by other variables not included in the model.

(b) The quality of the security aspects, safety aspects, equality aspects, regularity aspects, and affordability aspects can explain the comfort aspect variable by $77 \%$ and the remaining $33 \%$ is explained by other variables not included in the model.

\section{SEM Result}

The results of SEM analysis on the indirect effect of passengers and potential passengers are:

a. The indirect effect of the security aspect on the satisfaction aspect can be seen from the indirect effect of KSI on ETA which is -0.0015 which is the multiplication of the direct effect of the security aspect to the comfort aspect $(-0.05)$ with the comfort aspect to the satisfaction aspect $(0.03)$. This indirect effect is significant at the $5 \%$ level by taking into account the $t$ value of -0.34 .

b. The indirect effect of the safety aspect on the satisfaction aspect can be seen from the indirect effect of KSI on ETA, which is 0.0054 which is a multiplication of the direct effect of the safety aspect to the comfort aspect (0.18) with the comfort aspect to the satisfaction aspect (0.03). This indirect effect is significant at the $5 \%$ level by taking into account the $t$ value of 0.38 .

c. The indirect effect of the affordability aspect on the satisfaction aspect can be seen from the indirect effect of
Published By:

Blue Eyes Intelligence Engineering and Sciences Publication

91 (C) Copyright: All rights reserved.
KSI on ETA which is 0.0108 which is the multiplication of the direct effect of the affordability aspect to the comfort aspect $(0.36)$ with the comfort aspect to the satisfaction aspect (0.03). This indirect effect is significant at the $5 \%$ level by taking into account the $t$ value of 0.39 .

d. The indirect effect of the equality aspect on the satisfaction aspect can be seen from the indirect effect of KSI on ETA, which is 0.0009 which is the multiplication of the direct effect of the equality aspect to the comfort aspect (0.03) with the comfort aspect to the satisfaction aspect (0.03). This indirect effect is significant at the 5\% level by taking into account the $t$ value of 0.32 .

e. The indirect effect of regularity on the satisfaction aspect can be seen from the indirect effect of KSI on ETA, which is 0.0114 which is the multiplication of the direct effect of the regularity aspect to the comfort aspect (0.38) with the comfort aspect to the satisfaction aspect (0.03). This indirect effect is significant at the $5 \%$ level by taking into account the $t$ value of 0.38 .

Thus it can be stated that in the passenger data and the potential for Trans Jogja passengers all indirect effects (security aspects, safety aspects, affordability aspects, equality aspects, regularity aspects) on the satisfaction aspect through the comfort aspect are able to mediate the relationship between security aspects, safety aspects, aspects affordability, aspects of equality, aspects of regularity to aspects of satisfaction even though the indirect effect is relatively small.

\section{CONCLUSION}

The passengers of Trans Jogja are varied and dominated by workers and students coming not only within the city of Yogyakarta but also the surrounding regions such as Purworejo, Kulon Progo, Magelang, and Klaten. The characteristics of these passengers are highly educated and in productive age. These passengers are aware of the quality of service provided by Trans Jogja as some have also become the loyal passengers since its initiation. Two models are used to measure the satisfaction aspect, namely comfort moderation and satisfaction moderation. In accordance with the current on-field condition of Trans Jogja, the comfort moderation model provides the most relevant result in which Trans Jogja service needs to be improved such as providing roof for the bus stop so that passengers to protect passengers from rain and sun light. Also pedestrian access needs to be provided to increase the security of the passengers for several stops which are exposed directly to traffic.

\section{ACKNOWLEDGMENT}

The research presented on this manuscript is supported by the Research Directorate (DirLit-LPPM) of Universitas Gadjah Mada, Yogyakarta, Indonesia.

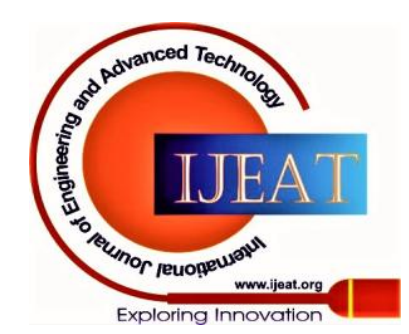




\section{REFERENCES}

1. Greer, M.R., 2011, Transport Utilization: The Case of Auckland. Journal of Public Transportation, 14 (2), pp: 53.

2. Ansusanto, D., Munawar, M., Priyanto, S., And Wibisono, B.H., (2014). The Effect of Land Use Change on the Assignment of the Yogyakarta Urban Road Network. FSTPT International Symposium, Jember University.

3. Institute for Transportation and Development Policy,(2016). The Bus Rapid Transit Standard. Institute for Transportation and Development Policy: India.

4. Lefrant, L. I. R., (2003). Planning for City Bus Public Transport with the Buy The Service System in Yogyakarta City Study. Thesis. Master of Transportation Systems and Engineering, Gadjah Mada University.

5. Goetsch, D.L., Stanley B. D., 2000, The Total Quality Approach to Quality Management, 3rd. New Jersey: Prentice Hall.

6. Sigit P, and Imam M.,(2015). Pedoman Evaluasi Kinerja Angkutan Umum. Yogyakarta : Beta Offset.

7. Kline, 2011, Principle and Practice of Structural Equation Modeling, Third Edition. The Guilford Press.

8. Yamin, S., (2014).Lisrel Data Processing Secrets. Jakarta: Mitra Wacana Media.

\section{AUTHORS PROFILE}

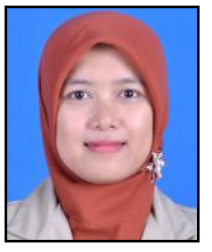

Nur Seta Mulyasari, student of Master Programme in Transport System and Engineering, Department of Civil and Environmental Engineering, Faculty of Engineering, Universitas Gadjah Mada, Yogyakarta. She studied her bachelor degree in School of Land Transport (STTD), under the Ministry of Transportation, Indonesia. Ever since her graduation from STTD, she has become a staff in the Department of Transportation of Bantul Regency, Yogyakarta, Indonesia. She serves as a program analyst and planning in the division of land transportation. Her research field of interest is in public transport planning and traffic engineering management.

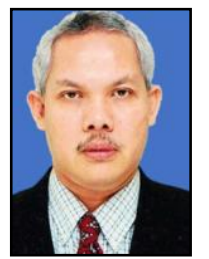

Sigit Priyanto, professor in transport system and engineering under the Department of Civil and Environmental Engineering, Faculty of Engineering, Universitas Gadjah Mada, Yogyakarta. His teaches the introduction to transport engineering, traffic mangement, and traffic safety for the bachelor programme of the department. Meanwhile, for the graduate programme, he teaches traffic safety, traffic modeling, air and water transport management, as well as special topic in traffic safety for children. His research interest includes public transport service, transport safety, multimodal transport, and transport policy.

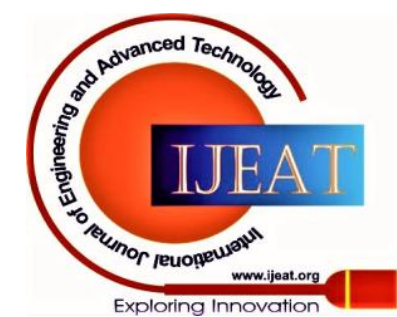

